\title{
Vibrobase insulation of a building excited by the technical seismicity effect of tube railway operation
}

\author{
D. Makovička ${ }^{1} \&$ D. Makovička $\mathrm{Jr}^{2}$ \\ ${ }^{1}$ Czech Technical University in Prague, Klokner Institute, Czech Republic \\ ${ }^{2}$ Static and Dynamic Consulting, Czech Republic
}

\begin{abstract}
This paper deals with the application of an elastic elastomer layer at foundation base level in order to eliminate excessive vibrations propagating to the assessed building through the geological environment from an underground railway station structure. The dominant vibrations propagate as non-stationary vibrations through the subsoil from the tube structure in the close vicinity of the analysed building structure. For response analysis, the measured time histories in the construction area were selected and then the typical response was used as an input for a dynamic analysis of the structure. The solution of vibration transfer from the subsoil to the structure is demonstrated using the example of a multistorey reinforced concrete building, founded on a dual foundation plate. An antivibration layer of rubber has been designed between the two plates. Two 3-D numerical models of the building take into account the individual storeys, firstly together with the lay-out of the rubber distribution in the foundation part and secondly without this rubber part.

Keywords: technical seismicity, vibro-base insulation, elastomer, dynamic analysis, response prognosis.
\end{abstract}

\section{Introduction}

The dynamic effects of subsurface traffic propagating through the ground environment into the ambient buildings of urban agglomerations have been acquiring ever increasing importance. Construction firms try to use the areas in the proximity of underground lines because of their lucrative location, usually for residential construction. It is these structures erected in the proximity of 
underground tunnels or directly above them in the case of shallow tunnels that are threatened by vibrations from underground traffic.

Trains running through underground tunnels produce vibrations which, together with the vibrations from a wide range of constituents of the underground railway, such as ventilation fans and escalator drives, propagate from the source to more distant structures. As a rule, these vibrations propagate into building foundations at the foundations/subsoil interface. Vibrations produced by subsurface traffic usually do not threaten the safety of structures. Nevertheless, they may be significant because of their undesirable impacts on people living or working in the residential or office parts of the building, especially due to their tuning.

\section{Loading effect of underground traffic}

The character of vibrations depends on their parameters at their source, i.e. the character of the train motion, the structure and occupancy of the rolling stock, the geometry and characteristics of the permanent way (above all, the fastening of the rails, etc.), the structure of the tunnel or station, the parameters of the equipment of the tunnel or station, etc. The magnitude of the vibrations is influenced not only by the vibration parameters at the source, but also by the composition of the geological environment in the proximity of the underground railway, i.e. the route from the source to the threatened structure. Last but not least, the magnitude of these vibrations may be increased or damped by the actual execution of the structure loaded by them.

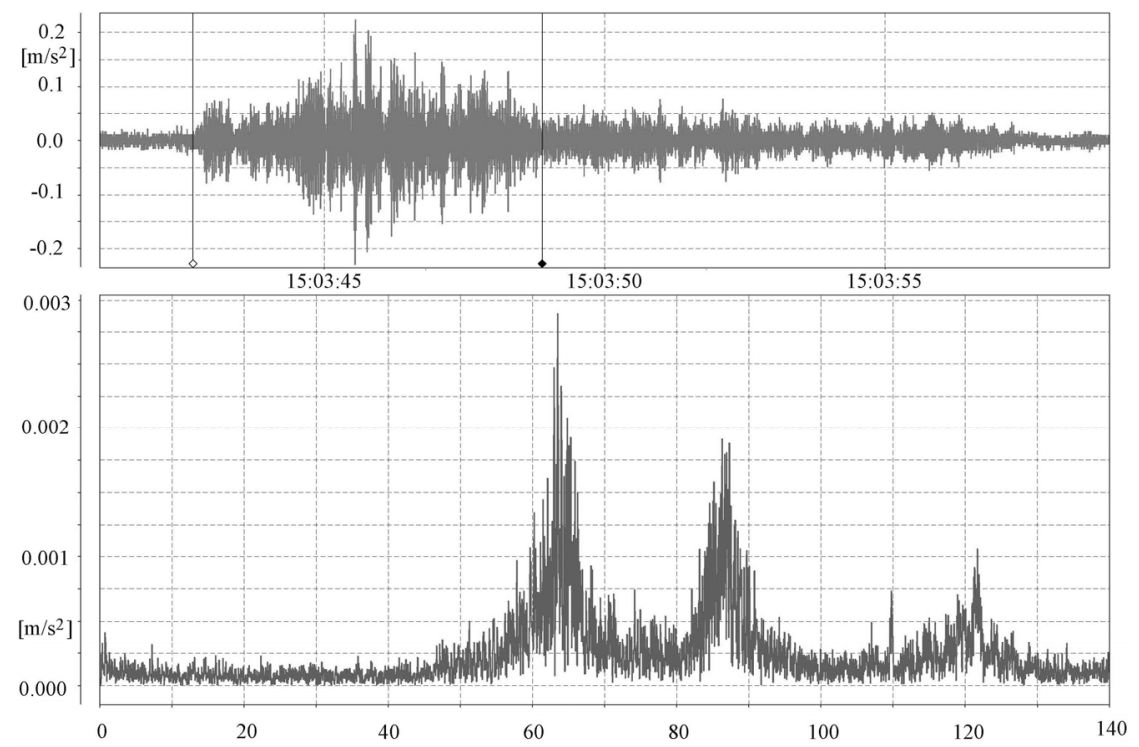

Figure 1: $\quad$ Measured vertical of the underground station excited by a train pass (the whole course, FFT spectrum). 
a)

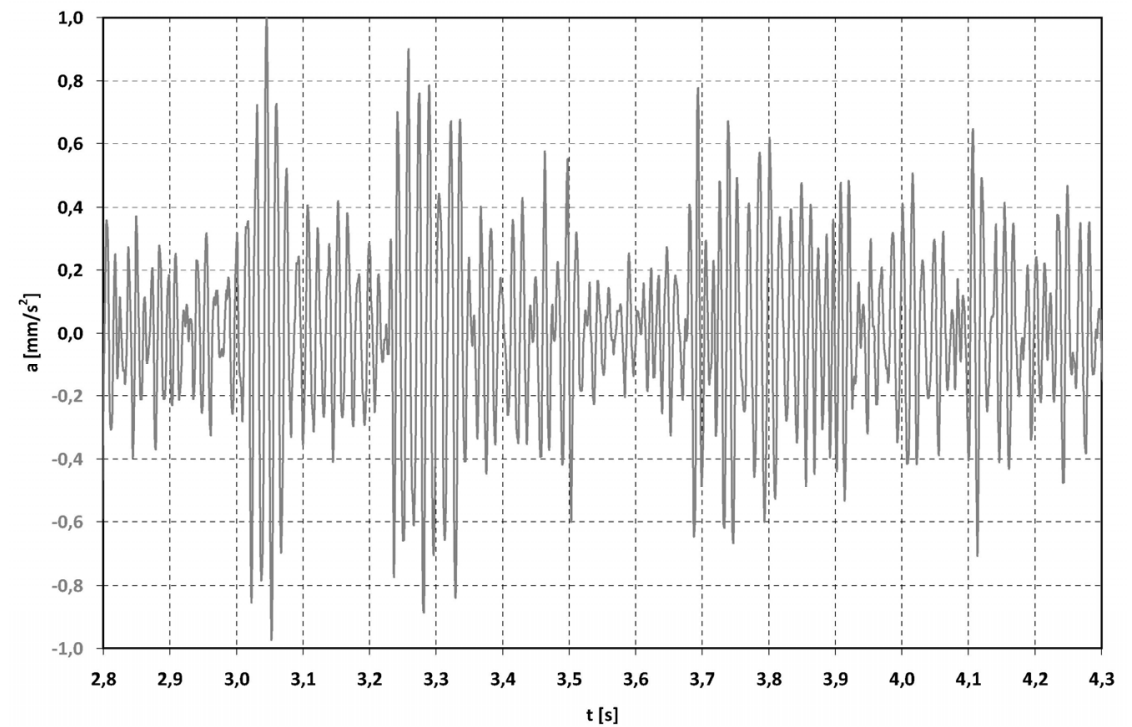

b)

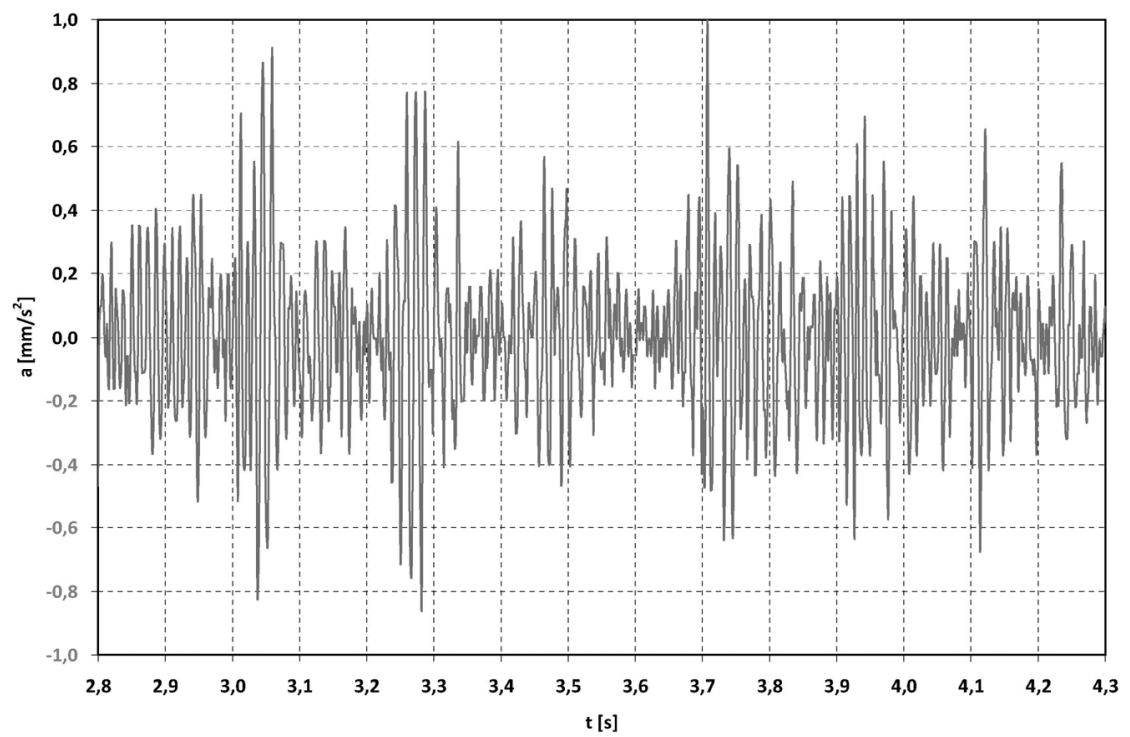

Figure 2: Selected parts of vibration excitation, a) vertical direction, b) horizontal direction.

When planning the correct measures for a structure that we intend to protect against excessive vibrations, we therefore need to know the amplitude level and the frequency structure of the vibrations which will propagate from the underground into the building. However, the measured real characteristics of the 
vibrations may show considerable mutual differences, because the magnitude of the vibrations and their frequency structure depend not only on the general parameters (train design, permanent way, structures of stations and tunnels, etc.) but also on the local parameters on the site (particularly the composition of the geological environment, foundation design, etc.) A responsible designer of measures for reducing vibration transfer into the structure to be protected therefore needs, first of all, to perform vibration measurements on site, and to evaluate them, preferably at the foundation base level. These measurements produce typical histories of vibrations affecting selected parts of the structure (Fig. 1 and Fig. 2), which can be considered as the dynamic load of the future or existing structure at its foundation level. This vibration load has a non-stationary character.

\section{Elastic support of the structure at its foundation level}

An effective method for reducing the vibration level of the protected structure (Fig. 3) as a whole with reference to its foundation structures (plate, piles, strips, etc.) is to spring it from the foundations. In our case, the multistorey reinforced concrete building (Fig. 3) is founded on the base plate. On top of this plate an antivibration layer of rubber has been designed. Above the rubber there is an upper foundation plate in which the cast-in-place skeleton building structure is constrained. The principle involves consistent separation of the upper part of the structure from the foundation structure by an elastic layer. The thickness of this continuous elastic layer or of blocks of several strata of this material, and their distribution, must be determined from the mechanical properties of the rubber (particularly its stiffness) and its static prestress on the basis of a static and dynamic analysis of the whole building.

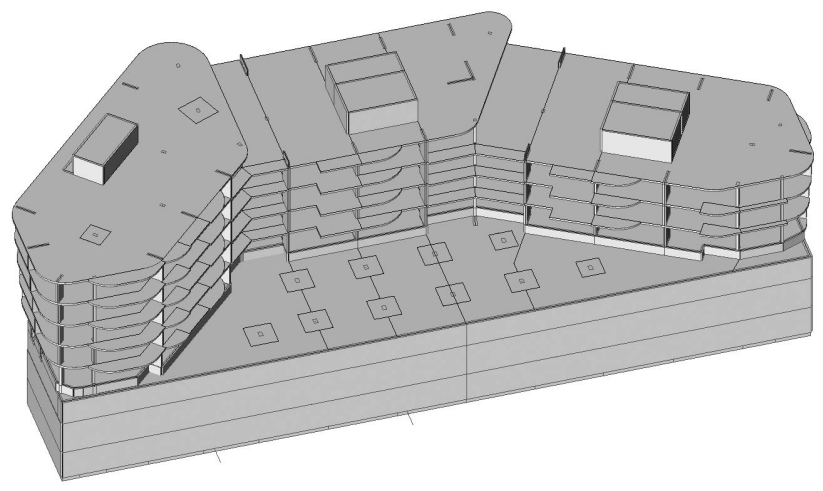

Figure 3: Calculation model.

The mechanical characteristics of the antivibration rubber layer were determined by laboratory tests of $500 \times 500 \times 30 \mathrm{~mm}$ samples that were used to form the vibration-resistant layer. The rubber blocks (slabs) are butt-jointed (not interlocked) in a single layer with $3-5 \mathrm{~mm}$ joints enabling the rubber to buckle, thus assuring identical conditions of deformability and, consequently, stiffness corresponding to the conditions at the foundation base. 
The advantage of rubber layers is that they provide sufficient damping to reduce the resonance peaks of the vibrations of the elastic supported structure.

\section{Structure analysis}

The calculation model takes into account the individual storeys, broken down into the floor, foundation and roof slabs, columns, load-bearing walls and peripheral and interior girders. The layer of rubber was considered as the elastic subsoil of the Winkler-Pasternak model below the whole area of the upper part of the foundation plate. The rubber stiffness in the theoretical model takes into account the results of experimental tests on these materials. The mass of the floor and the foundation plates includes the masses of the non-load-bearing components (thin partitions, floorings, etc.) as well as the equivalent of the live loads of floors, roof and terraces.

The natural vibrations were computed for the analyzed building structure. For the dynamic response to the effects of external actions (traffic), the lowest possible tuning of the rubber-mounted structure is decisive. This manifests itself, on the one hand, by flexural vibrations of the vibroinsulated building in the environs of $1.75 \mathrm{~Hz}$, and, on the other hand, by vertical and horizontal translative vibrations of the building as a whole or by torsional vibrations. The lowest six vibration modes are shown in Fig. 4. Not only the basic natural vibration modes but also the higher natural vibration frequencies of the individual storeys, possibly columns and walls, balconies, etc., appear in the computation, which makes the response of the building on each storey slightly different (higher, lower, possibly with antinodes on different sites).

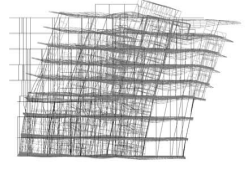

$1.75 \mathrm{~Hz}$

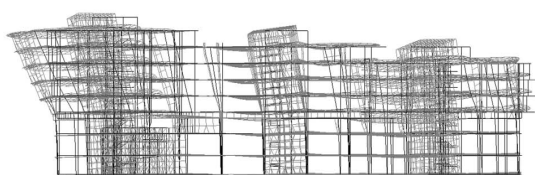

$2.43 \mathrm{~Hz}$

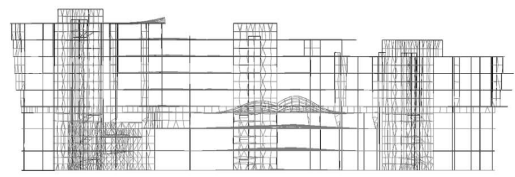

$5.32 \mathrm{~Hz}$

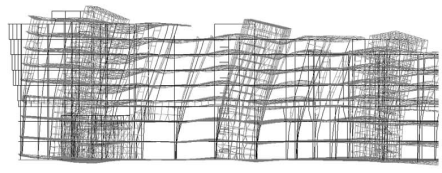

$2.33 \mathrm{~Hz}$

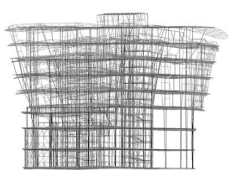

$4.46 \mathrm{~Hz}$

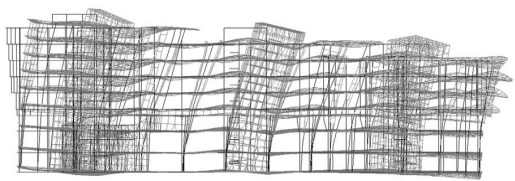

$5.35 \mathrm{~Hz}$

Figure 4: The lowest six natural vibration modes of a vibroinsulated structure. 
The difference between the calculated natural frequencies for the structure with and without vibroinsulation is very small (Table 1).

Table 1: $\quad$ Effect of vibroinsulation on natural frequency $[\mathrm{Hz}]$ values.

\begin{tabular}{|c|c|c|}
\hline \multicolumn{2}{|c|}{ Natural frequency $[\mathrm{Hz}]$} & \multirow[b]{2}{*}{ Character of natural mode } \\
\hline $\begin{array}{r}\text { with } \\
\text { vib }\end{array}$ & vibroinsulation & \\
\hline 1.75 & 1.91 & $\begin{array}{l}\text { Bending of the whole structure in perpendicular } \\
\text { direction }\end{array}$ \\
\hline 2.33 & 2.53 & $\begin{array}{l}\text { Bending of floor plates and bending of the whole } \\
\text { structure in longitudinal direction }\end{array}$ \\
\hline 2.43 & 2.54 & $\begin{array}{l}\text { Rotation of the whole structure round the vertical } \\
\text { axis }\end{array}$ \\
\hline 4.46 & 4.56 & $\begin{array}{l}\text { Rotation of the whole structure round the vertical } \\
\text { axis and floor slab bending of the higher storeys }\end{array}$ \\
\hline 5.32 & 5.53 & Higher modes of floor slab bending \\
\hline 5.35 & 5.57 & $\begin{array}{l}\text { Bending of some floor plates of the lower storeys } \\
\text { and roof }\end{array}$ \\
\hline 5.43 & 5.76 & Bending of some floor plates of the middle storey \\
\hline 5.56 & 5.82 & \\
\hline 5.87 & 6.00 & Higher modes of floor slab bending \\
\hline 5.99 & 6.19 & \\
\hline
\end{tabular}

The dynamic load, i.e., the vibrations (Fig. 2), was introduced into the model independently for both directions as a normalized load and with the identical phase all over the foundation plate. The vibrations of the building produced by underground traffic were predicted by the response analysis of the whole system. Extremes of relative displacements in all the storeys are shown in the Tab. 2. The time histories for selected points on all the floors located on the chosen vertical line on the margin of the left highest structure part on its rear side are shown in Fig. 5. The most intensive vibrations can be observed in the proximity of columns, balconies, terraces and structural parts situated on the underground side. With increasing height, this excitation mode will manifest itself by vibrations of the building in one of the natural frequencies of the structure. More significant influence of vibration is in most cases limited to the lowest two or three storeys. In the higher storeys, the time characteristic of the vibrations is divided into lower frequencies. Another element reducing the vibration level in the individual storeys may be the non-load-bearing partitions, floating floors, carpet floorings, etc. 
Table 2: $\quad$ Extremes of relative floor displacements under vertical excitation.

\begin{tabular}{|c|c|c|c|c|c|c|c|c|}
\hline \multirow{4}{*}{ Floor level } & \multicolumn{4}{|c|}{ Insulated structure } & \multicolumn{4}{|c|}{ Noninsulated structure } \\
\hline & \multirow{2}{*}{\multicolumn{2}{|c|}{$\begin{array}{c}\begin{array}{c}\text { Vertical } \\
\text { excitation }\end{array} \\
\mathrm{u}_{\mathrm{z}}\end{array}$}} & \multicolumn{2}{|c|}{$\begin{array}{c}\text { Horizontal } \\
\text { excitation }\end{array}$} & \multicolumn{2}{|c|}{$\begin{array}{c}\text { Vertical } \\
\text { excitation }\end{array}$} & \multicolumn{2}{|c|}{$\begin{array}{l}\text { Horizontal } \\
\text { excitation }\end{array}$} \\
\hline & & & & & & & & \\
\hline & Max & Min & Max & Min & Max & Min & Max & Min \\
\hline$-3^{\text {rd }}$ Floor & 1.00 & -0.76 & 1.00 & -0.83 & 1.00 & -1.00 & 1.00 & -1.00 \\
\hline$-2^{\text {nd }}$ Floor & 1.22 & -1.29 & 0.96 & -1.07 & 1.43 & -1.00 & 1.28 & -1.89 \\
\hline$-1^{\text {st }}$ Floor & 1.24 & -0.97 & 0.89 & -0.89 & 1.00 & -1.00 & 1.12 & -1.23 \\
\hline$+1^{\text {st }}$ Floor & 0.87 & -0.92 & 0.70 & -0.59 & 0.85 & -0.82 & 1.18 & -1.49 \\
\hline $\begin{array}{r}+1^{\text {st }} \text { Floor, } \\
\text { balconies }\end{array}$ & 1.25 & -1.22 & 0.90 & -1.05 & 0.85 & -1.09 & 1.12 & -1.56 \\
\hline$+2^{\text {nd }}$ Floor & 0.74 & -0.64 & 1.00 & -1.02 & 0.70 & -0.53 & 0.85 & -0.91 \\
\hline $\begin{array}{r}+2^{\text {nd }} \text { Floor, } \\
\text { balconies }\end{array}$ & 0.84 & -0.92 & 1.05 & -1.07 & 1.02 & -0.91 & 0.96 & -0.91 \\
\hline$+3^{\text {rd }}$ Floor & 0.70 & -0.69 & 0.85 & -0.76 & 0.54 & -0.72 & 0.91 & -0.95 \\
\hline $\begin{array}{r}+3^{\text {rd }} \text { Floor, } \\
\text { balconies }\end{array}$ & 0.92 & -0.79 & 0.95 & -0.76 & 1.02 & -0.72 & 0.76 & -0.84 \\
\hline$+4^{\text {th }}$ Floor & 0.73 & -0.72 & 1.08 & -1.13 & 0.63 & -0.51 & 0.81 & -1.04 \\
\hline $\begin{array}{l}+4^{\text {th }} \text { Floor, } \\
\text { balconies }\end{array}$ & 0.96 & -0.95 & 0.57 & -0.53 & 0.81 & -0.84 & 0.65 & -0.88 \\
\hline$+5^{\text {th }}$ Floor & 0.66 & -0.66 & 1.08 & -0.93 & 0.63 & -0.56 & 0.81 & -1.19 \\
\hline $\begin{array}{r}+5^{\text {th }} \text { Floor, } \\
\text { balconies }\end{array}$ & 1.24 & -1.21 & 0.55 & -0.44 & 1.33 & -1.35 & 0.38 & -0.70 \\
\hline$+6^{\text {th }}$ Floor & 0.69 & -0.71 & 0.85 & -1.04 & 0.52 & -0.47 & 1.09 & -1.32 \\
\hline $\begin{array}{r}+6^{\text {th }} \text { Floor, } \\
\text { balconies }\end{array}$ & 1.44 & -1.32 & 0.72 & -0.81 & 1.02 & -1.05 & 0.84 & -1.14 \\
\hline
\end{tabular}

An observation of the response computation during vertical versus horizontal excitation reveals that the horizontal excitation level (non-normalised) is lower than the vertical excitation level - according to the measurements, approximately twice as low. Moreover, the response to horizontal excitation is, as a rule, of very low frequency, and it is also damped faster than in the case of vertical excitation. 
a)

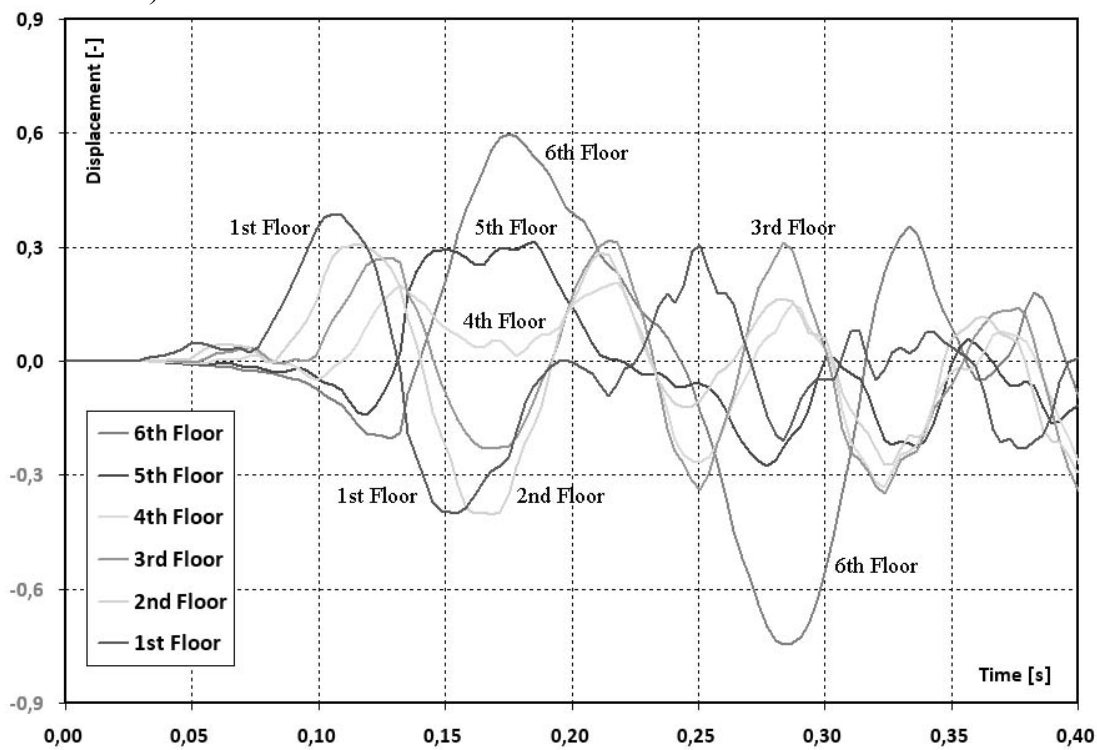

b)

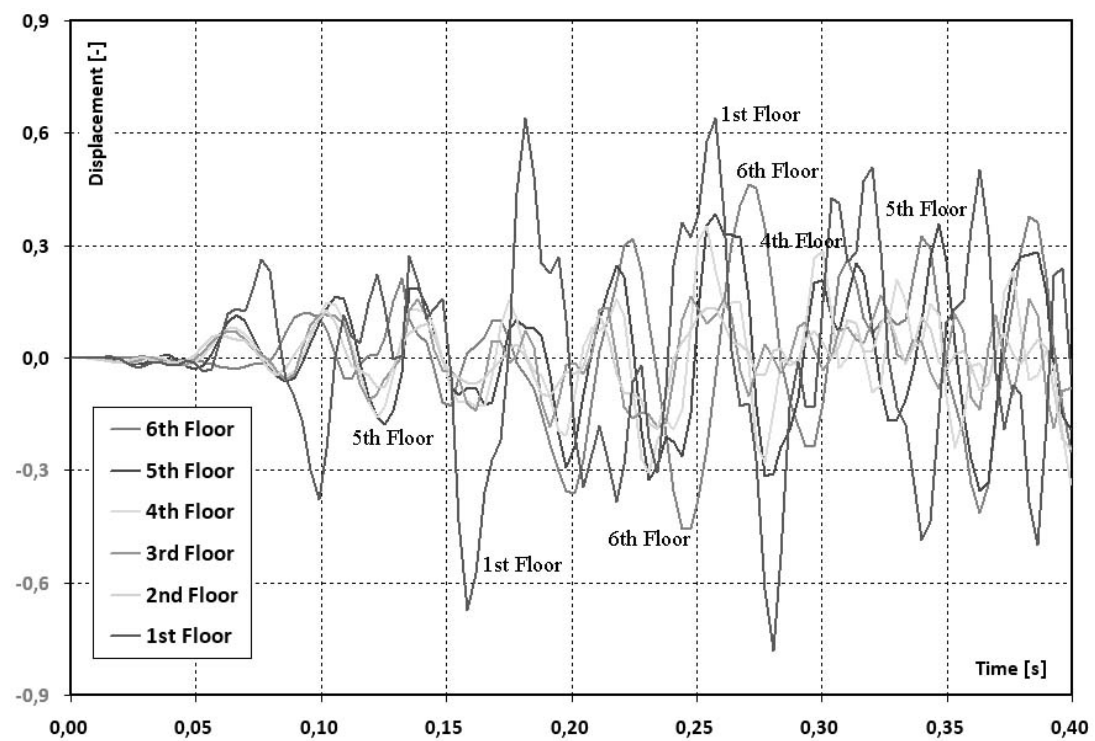

b)

Figure 5: Time histories of relative displacements on line $\mathrm{B}$, a) vertical direction, b) horizontal direction. 


\section{An assessment of the effectiveness of springing}

An assessment of the effectiveness of the sprung system can be based on a comparison between the measured vibrations (Fig. 1) and the vibration level of the individual storeys in the sprung building.

The measured dominant excitation frequencies of underground train traffic are $63 \mathrm{~Hz}$ and $87 \mathrm{~Hz}$ on the frequency peaks (Fig. 1). The springing of the building will shift its dominant vibrations into the range of the lowest natural frequencies (from $1,7 \mathrm{~Hz}$ to about $20 \mathrm{~Hz}$, see Fig. 5) of the sliding or flexural vibrations of the building as a whole. For frequencies of up to $20 \mathrm{~Hz}$, this maximum response acceleration value corresponds approximately to the effective acceleration $a_{\mathrm{RMS}}$ according to Table 3 .

Table 3: $\quad$ Prognosis of maximum floor vibration.

\begin{tabular}{|l|c|c|c|c|}
\hline $\begin{array}{c}\text { Excitation } \\
a_{\mathrm{RMS}} \\
{\left[\mathrm{mm} / \mathrm{s}^{2}\right]}\end{array}$ & \multicolumn{2}{|c|}{ Vertical excitation } & \multicolumn{2}{c|}{ Horizontal excitation } \\
\hline & $\begin{array}{c}\text { Middle part } \\
\text { of floors }\end{array}$ & Balconies & $\begin{array}{c}\text { Middle part } \\
\text { of floors }\end{array}$ & Balconies \\
\hline Amplification & 0.92 & 1.44 & 1.08 & 1.07 \\
\hline & \multicolumn{4}{|c|}{ Response $a_{\text {RMS }}\left[\mathrm{mm} / \mathrm{s}^{2}\right]$} \\
\hline $0.80-0.84$ & $0.736-0.773$ & $1.152-1.210$ & & \\
\hline $0.22-0.24$ & & & $0.238-0.259$ & $0.235-0.257$ \\
\hline
\end{tabular}

The above results (Tables and Fig. 5) show that the influence of springing will manifest itself by redistribution of the dominant vibrations into the low frequency range of the springing and by the practically negligible amplitude range of the vibration level in comparison with the initially dominant excitation frequencies (Fig. 1).

\section{Conclusion}

This paper deals with the application of an elastic antivibration layer at foundation base level in order to eliminate excessive vibrations propagating to the assessed building through the geological environment from an underground railway structure. When the train is in motion, the dominant vibrations are transferred to the environs in the form of non-stationary vibrations produced by the pass of the train and of the tunnel station structure vibration (in our case).

The histories of the measured vibrations were used as loads applied to a modelled building structure at the foundation base of which, as an alternative, a separating elastic rubber layer had been designed. The response of the vibroinsulated structure is compared with the non-isolated structure. The computed vibration histories reveal that the vibrations of the sprung structure are 
decreased in almost all the above-ground storeys. The effectiveness of the springing is determined by the frequency tuning of the sprung structure. The lower the tuning of the structure based on springs (the lower the dominant natural frequencies), the greater the decrease in the higher vibration frequencies and acoustic frequency effects propagating into the structure from its geological environment.

More significant influence of vibration is in most cases limited to the lowest two or three storeys. The predicted vibrations in the individual storeys were shown for a model with and without insulation, and were compared with the level of excitation vibrations at the foundation base. In the case of hard inelastic placing of the building on subsoil without springing, the vibrations would propagate from the subsoil in the whole frequency interval directly into the building structure, practically without decreasing. The applied springing is, consequently, a very efficient instrument for reducing the transfer of vibration from the soil to the interior parts of the building.

\section{Acknowledgement}

This research was supported as a part of the research projects in GAČR 103/08/0859 "Structure response under static and dynamic loads caused by natural and man induced activity", for which the authors would like to thank the Agency.

\section{References}

[1] Makovička, D. \& Makovička, D., Jr., Response analysis and vibroinsulation of buildings subject to technical seismicity, Earthquake Resistant Engineering Structures VII, WIT Press, Southampton, UK, pp. 197-205, 2009.

[2] Makovička, D. \& Makovička, D., Jr., Structure insulation exposed to excessive vibration of underground traffic (in Czech), Stavebni obzor, 14/1, 2005.

[3] Jacquet, T. \& Heiland, D., Tieffrequente Bauwerken-Kopplungen als Schutz gegen Erschütterungen, Gerb Berlin, 2002.

[4] Kay, H., Nachträgliche Schwingungsisolierungen von Gebäuden, Spezialtiefbau, TIS 2001, No. 4. 